
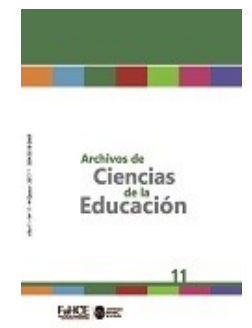

Archivos de Ciencias de la Educación, Volñ. 11, nº 11, 2016, e022. ISSN 2346-8866

Universidad Nacional de La Plata.

Facultad de Humanidades y Ciencias de la Educación.

Departamento de Ciencias de la Educación.

\section{La formación del magisterio en la planificación cultural del peronismo (1948-1949)}

\author{
Training teachers in cultural planning of Peronism (1948-1949)
}

\section{Gabriela Verónica Ferreyra}

Universidad Nacional de Tres de Febrero, Argentina | gferreyra@untref.edu.ar

\section{PALABRAS CLAVE RESUMEN}

Peronismo

Durante el primer gobierno de Perón (1946-1952) el magisterio fue receptor de una serie de medidas que apuntaron a modificar algunas características tradicionales de su formación. La regulación de estos asuntos pedagógicos se produjo en un contexto de ampliación de la educación y la cultura a

Consejo Nacional de todos los sectores de la población, de reorganización institucional e incorporación de técnicos especialistas en la burocracia. Este trabajo analiza las medidas impulsadas por el Consejo Nacional de Educación destinadas a renovar la formación cultural del docente. El recorte abarca el período 1948-

Magisterio 1949, etapa previa a la conformación del Ministerio de Educación, en la cual la burocracia encargada de la enseñanza primaria puso en marcha un importante avance en la capacitación profesional y cultural del sector.

Formación cultural

KEYWORDS

Peronism

\section{ABSTRACT}

During the first government of Juan Peron (1946-1952) teaching trainee centers were the goal of measures aimed at changing some traditional features of their training. The regulation of pedagogical issues took place in a context of growth of the access education and culture consumption to all sectors of the population, institutional reorganization and coalescence of technical experts in the bureaucracy. The paper analyzes the measures promoted by the National Education Council linked to renew the cultural education of teachers. The period chosen is 1948-1949, before the Ministry of Education was created, because during these years the bureaucracy in charge of primary education launched a significant progress in professional and cultural training of primary teachers. 


\section{Introducción}

El Consejo Nacional de Educación (en adelante CNE), órgano público que administraba la educación primaria argentina en la Capital Federal, los territorios y las escuelas nacionales de las provincias, ocupó un rol fundamental en la regulación de los asuntos pedagógicos. Durante los primeros años peronistas (1946-1952), el ímpetu de renovación que traía consigo el nuevo gobierno impulsó la revisión de su acción y, en un contexto de ampliación de la cultura a todos los sectores de la población y de reorganización institucional e incorporación de técnicos especialistas en la burocracia, emitió nuevas directivas destinadas a modificar algunos aspectos de la formación del docente.

La educación primaria durante el peronismo ha sido estudiada desde diferentes perspectivas: desde las modificaciones en los planes de estudio (Gvirtz, 1991; Somoza Rodríguez, 2006), el impacto de los nuevos contenidos dentro de la institución escolar (Gvirtz, 1999; Fiorucci, 2012; Plotkin, 2007), los mecanismos destinados a la generación de un consenso político (Plotkin, 2007; Rein y Rein, 1996), la creación del Ministerio de Educación y su injerencia en el proceso de centralización educativa (Cammarota, 2010), la relación entre las reformas curriculares y las demandas de la sociedad civil (Bernetti y Puiggrós, 1993), y los discursos pedagógicos de la época (Carli, 2002; Bernetti y Puiggrós, 1993). En la mayor parte de estos estudios el magisterio aparece como una herramienta requerida por el Estado fundamentalmente para la divulgación de la propaganda política oficial.

Este artículo presenta un avance de la tesis en la que estudio las ideas y acciones del CNE en torno al proyecto de reforma curricular de 1948. En este caso, se analizan las medidas destinadas a renovar la formación cultural del magisterio. El recorte abarca el período 1948-1949, etapa previa a la conformación del Ministerio de Educación, en la cual burocracia encargada de la enseñanza primaria priorizó la capacitación profesional y cultural del sector. En la primera parte, se aborda la articulación entre el pensamiento pedagógico de los funcionarios peronistas y la redefinición del perfil del maestro y de la institución escuela. En la segunda parte, se describen las disposiciones del CNE destinadas al docente y su relación con la planificación cultural oficial.

\section{Los primeros años peronistas y la redefinición oficial del perfil del maestro en ejercicio (1948-1949)}

Durante los primeros años de gestión, el gobierno justicialista puso en marcha una política dirigida a mantener a los alumnos en la institución escolar. Según los datos que ofrecían los directores, año tras año la matrícula de las escuelas primarias nacionales de la Capital Federal disminuía. A modo de ejemplo, en 1943 comenzaron en las escuelas primarias públicas diurnas 237.551 alumnos y terminaron 235.376 (Educación Común en la capital, provincias y territorios nacionales 1943, 1945, p. 15) y en 1947, se inscribieron un total de 215.166 y finalizaron 209.437 (Educación Común en..., 1949, p. 11). La solución del problema comenzaba, según el pensamiento oficial, en dotar de un nuevo sentido a la enseñanza.

El nuevo gobierno entendió que la causa fundamental del desgranamiento estaba en la impronta positivista del sistema educativo. Como menciona Miriam Southwell (2011), la escuela normal marcaba rígidamente los límites entre el afuera y el adentro, racional y dueña del conocimiento, se 
pensó a sí misma propietaria de una cultura letrada de cuño europeo y desconoció aquello que los individuos traían como experiencia propia y diferente al mundo escolar. En 1947 el subsecretario de Instrucción Pública Jorge Pedro Arizaga, señalaba que la formación normalista "mantuvo a nuestra escuela en una actitud anacrónica con respecto a la evolución social, privándola de la necesaria elasticidad para adaptarse al espíritu y a las necesidades de los nuevos tiempos” (1947, p. 41).

Esta discusión, sin embargo, no fue una innovación del peronismo. Durante las primeras décadas del siglo XX comenzaron a circular diferentes ideas reformistas que, con el correr de los años, se fueron instalando en los discursos de docentes, pedagogos y funcionarios. En 1946 el Estado fijó la enseñanza espiritual, manual e intelectual como el eje principal de los mensajes oficiales a nivel nacional. Según Arizaga, el proyecto pedagógico:

reclama ineludiblemente la presencia del maestro culto en toda la significación del concepto. La función del maestro se extiende así, desde el cultivo del potencial psicofísico de cada niño hasta el logro de los ideales de la educación; desde el hacer didáctico, hasta la meditación axiológica; desde la investigación de la naturaleza humana hasta el conocimiento de las necesidades sociales y los objetivos nacionales (1947, p. 48).

En un contexto de democratización de la enseñanza primaria, esta definición implicó un reacomodamiento de la práctica en el aula. Como menciona Pablo Pineau (1994), el peronismo reconoció al pueblo como portador de significantes sociales previos y así entendió la cuestión escolar. El mensaje oficial se distanció del objetivo homogeneizador de la escuela decimonónica y exigió un docente capaz de responder a una realidad con "problemas de carácter social [que necesitaban] una solución más acorde con los momentos que se vive” (Expediente 27.747, CNE, 1948).

\subsection{El maestro y su preparación cultural: el escenario previo}

La formación del maestro fue una preocupación compartida por los diferentes actores que conformaban el sistema. En 1947, desde la revista La Obra se reclamó con fuerza la intervención del Estado para la "obtención de una sólida cultura general y no una menos sólida capacitación técnica” en los estudios de los educadores (25 de abril de 1947, p. 107). Consideró que la profesión requería, además del aspecto vocacional y las aptitudes innatas, la posesión de conocimientos científicos e instrumentales, "una ilustración general sólida y amplísima, una instrucción técnica acabada y una cultura exquisita elevada al más alto grado posible” (10 de abril de 1947, p. 66).

Es necesario destacar que el interés por la ampliación de los saberes del maestro estuvo presente muchos años antes de la reforma de 1948. Según Lucía Lionetti, desde fines del siglo XIX y principios del XX se pretendió modificar el rumbo de la educación replanteando las políticas de formación del magisterio porque “... los maestros y maestras estuvieron en el centro de las críticas...Por eso se promovía un cambio en su formación pedagógica” (2007, p. 75). Así, El Monitor de la Educación Común sostenía en 1932:

No daremos una sola página, sin doctrina que acreciente y perfeccione el espíritu del maestro...habrá asimismo aquí más de un lugar para toda ciencia, como ha de haber 
sitio para las letras y las artes...Al lado de la Pedagogía, nada de la cultura, nada del pensamiento humano puede serle extraño al maestro verdadero (El Monitor de la Educación Común citado en Finocchio, 2009, p. 77).

Un director de escuela señalaba en 1935, que el hombre dedicado a la enseñanza debía ser "ante todo un intelectual, el mantenimiento y el desarrollo de su propia cultura [debían] ocupar el primer rango entre los deberes de quien se consagra a la educación” (El Monitor de la Educación Común citado en Finocchio, 2009, p. 77). Para el mismo período, la revista La Obra daba cuenta de la percepción que la sociedad expresaba sobre el magisterio. Según la publicación, "se clasifica a todo el magisterio dentro de la ruda afirmación del aforismo francés: Ignorant comme un maitre d'école” (25 de marzo de 1939, p. 29). Para modificar su situación, recomendaban, era obligación perfeccionarse y ampliar sus saberes, debían comportarse como hombres de cultura y de pensamiento, de ideas claras y de sólidas lecturas, con información para las exigencias del aula, versación pedagógica y didáctica, preparación literaria, filosófica y general (La Obra, 25 de marzo de 1939, p.30).

Durante los años cuarenta, el gobierno insistió en la planificación y racionalización de la esfera estatal. La necesidad de contar con cuerpos técnicos repercutió en la concepción que la burocracia tenía sobre las capacidades del maestro de grado en su rol de funcionario del Estado. El espíritu de época repercutió en las revistas educativas, La Obra, por ejemplo, hizo foco en la actualización y perfeccionamiento de las técnicas pedagógicas. En ese contexto, desaparecieron las secciones "Para el Hogar" y la "Página femenina”, poemas y reflexiones sobre "moral sexual femenina”, oferta de ropas, peinados, tapados, sombreros, zapatos, adornos y joyas, pieles, muebles para el hogar. También quedaron en el camino los temas relacionados con "el noviazgo, la escasez de candidatos o el temor a la soltería” y el matrimonio (Finocchio, 2009, 103). La demanda de un personal capacitado, requerido abiertamente por una parte de la prensa, los funcionarios y los editores de la revista, se reprodujo en avisos publicitarios que intentaron colaborar con el dominio de contenidos escolares.

A fines de la década del cuarenta, las páginas publicitaron desde material didáctico, artículos de librería, cancioneros, dramatizaciones, conferencias y discursos armados a pedido, hasta tratados de psicología aplicada y libros de la "Biblioteca de Ciencias de la Educación” que se ofrecían como "la formación cultural y profesional de maestros y profesores el desiderátum que más ahincadamente se procura alcanzar, mediante la renovación de los estudios pedagógicos” (La Obra, revista de educación, 25 de octubre de 1947). La ampliación de las funciones pedagógicas impulsó los pasos hacia la profesionalización del magisterio, y con ella, la reconstrucción identitaria de una arista de su formación. Este propósito, además de cubrirse con el material ofertado desde el sector privado, recibió el apoyo del CNE.

\section{EI CNE y la planificación cultural}

\subsection{La burocracia educativa (1948-1949)}

La regulación de los asuntos pedagógicos se produjo en un contexto de reorganización institucional e incorporación de especialistas en las áreas de incumbencia. En 1948, el CNE y la Subsecretaría de Instrucción Pública fueron reestructuradas con el fin de comenzar a establecer una coordinación 
general del sistema de manera unificada. Oscar Ivanissevich ocupó la flamante Secretaría de Educación con rango de Ministerio. Bajo su dependencia pasaron a estar, entre otras instituciones, la Subsecretaría de Educación (ex Subsecretaría de Instrucción Pública) con el profesor Jorge Pedro Arizaga como titular y el CNE, con el nuevo delegado interventor Federico Daus. Este funcionario era egresado del Instituto Nacional de Profesorado Secundario, vicedirector del Colegio Nacional de Buenos Aires y ejercía la docencia en la Universidad de Buenos Aires y en la Universidad Nacional de La Plata. Cuando asumió, designó para la Secretaría de Didáctica al profesor Prudencio Oscar Tolosa y al Dr. Luis Giordano. Estos nombramientos respondieron a los lineamientos propuestos en el Plan de Gobierno para 1947-1952 que señalaban "las designaciones de Vocales del Consejo Nacional de Educación recaerán siempre en personas de acreditada preparación o experiencia educacional” (Plan de Gobierno 1947-1951, 1946, p. 11). La elección demostró el interés oficial por la incorporación de técnicos conocedores de la situación áulica.

Jorge Pedro Arizaga había sido el promotor de la reforma en la orientación de la enseñanza. En “Aplicación del plan de gobierno en la enseñanza primaria”, la conferencia en la que explicaba los fundamentos de las reformas promovidas por el Primer Plan Quinquenal, da cuenta de la selección y apropiación de los elementos pedagógicos por parte del oficialismo, entre ellos, el paidocentrismo, el rechazo al enciclopedismo, la mecanización de los métodos didácticos y el alejamiento de los reclamos del ambiente. Entendía que la educación elemental debía fomentar el desarrollo de los intereses y aptitudes de cada niño, el desenvolvimiento integral de su personalidad y el trabajo tanto intelectual como manual (Arizaga, 1947). Estos aspectos coincidían con el recorrido pedagógico que habían realizado dos de los asesores del Interventor del CNE, Prudencio Oscar Tolosa y Luis Giordano.

La presencia de Tolosa y de Giordano en la Secretaría de Didáctica del CNE durante el período de aplicación del proyecto de reforma educativa peronista, 1948-1949, ponía en sintonía las funciones de la escuela con las políticas sociales del nuevo gobierno. El primero era maestro egresado del normal Mariano Acosta y profesor normal en Letras. Había sido colaborador especializado en el Instituto de Didáctica de la Facultad de Filosofía y Letras de la UBA, organismo creado en 1927 encargado de difundir el pensamiento y las propuestas metodológicas de los intelectuales del escolanovismo, entre ellos, María Montessori, John Dewey, Ovide Decroly, Adolphe Ferriére, Friedrich Fröebel, José Rezzano, Clotilde Guillén de Rezzano, Juan Mantovani y Lorenzo Luzuriaga. Había integrado la sección argentina de la Liga Internacional de la Nueva Educación, publicaba desde 1935 libros de lectura para la escuela primaria y, desde mediados de la década del treinta y hasta 1945, se había desempeñado como co-director de la revista La Obra. Giordano colaboraba desde los años treinta en El Monitor de la Educación Común con artículos sobre las asociaciones de padres, la cuestión social, el conocimiento del niño y las clínicas integrales infantiles. Estos funcionarios le dieron forma a las iniciativas que luego serían difundidas por los inspectores en las escuelas.

Si bien la burocracia educativa no tuvo un contacto directo con el ámbito de las manifestaciones artísticas, atendiendo al rol central de la escuela en la irradiación de la cultura apelando a diferentes canales para llevar el mensaje a oídos de los maestros. Por ejemplo, la definición realizada por un inspector, quien en un informe de observación de clase exhortó: 
La función social que compete a la escuela no puede reducirse a la diaria tarea de enseñar. Es mucho más amplia y para cumplirla, es necesario desplegar una intensa actividad que escape del límite de las aulas y para lo cual es indispensable vivir íntimamente vinculada a la población, conocer sus problemas, participar de sus inquietudes (Informe de observación. Expediente 222293-C-1948, 6 de septiembre de 1948).

O el comentario de El Monitor de la Educación Común, que expresó:

la finalidad y el objetivo de las artes, no es transmitir un conocimiento mayor al respecto, ni mayor actividad técnica, y sí cultivar la receptividad de los niños en las propias experiencias. A través de esta práctica de arte los niños amplían su propia capacidad para vivir y exigirán naturalidad mayor de sus propios sentimientos (octubre de 1948, p. 16).

Los funcionarios entendieron que, para ampliar la función de la escuela, debían acompañar las directivas con un plan de capacitación y actualización del sector docente. En 1948 el secretario de Educación Oscar Ivanissevich señaló una serie de puntos a seguir vinculados directamente con la cultura de los maestros. Su preparación, indicó, debía ser ampliada y actualizada "facilitando y estimulando el perfeccionamiento cultural” (Boletín de la Secretaría de Educación, 1948, p. 2407).

Entre las acciones para lograr ese objetivo, sugirió:

1-Difundir la creación de escuelas y cursos de perfeccionamiento docente y de extensión cultural en todo el país.

2-Facilitar y estimular la realización de viajes y excursiones de estudio por el país y por el extranjero.

3-Estimular toda manifestación de orden artístico y científico en los docentes.

4-Editar y distribuir gratuitamente, por el Consejo Nacional de Educación, libros para las bibliotecas infantiles y obras pedagógicas, didácticas y de información y cultura general para el maestro.

5-Gestionar la realización de conciertos y de funciones teatrales de alto valor artístico, para docentes (Boletín de la Secretaría de Educación, 1948, pp. 2407-2408).

De este modo, la planificación cultural destinada al magisterio se pensó en diferentes carriles vinculados, uno con el tiempo de ocio y otro, con el ámbito propiamente escolar, es decir, con el mejoramiento de la práctica áulica.

\section{2. ¿Qué hacer? Disposiciones oficiales destinadas a elevar la preparación cultural del maestro}

Los funcionarios peronistas destacaron la importancia del trabajo de los educadores para concretar el proyecto educativo diseñado en el Primer Plan Quinquenal (1947-1952). En palabras de un inspector de Zona de Córdoba, los maestros eran "agentes del Estado y como tales, [debían] al 
Estado, representado por las autoridades constituidas...todo el acatamiento, consideración y colaboración que ellas nos pidan” (Expediente 28226-C-1948). Según Miguel Somoza Rodríguez (2002), su papel era crucial para el desarrollo y consolidación de la hegemonía política, debido a que Perón consideraba que las estructuras estatales eran la manera más idónea para difundir su doctrina y los maestros y profesores, agentes naturales para la enseñanza. La mirada del CNE hacia el magisterio, sin embargo, no estuvo centrada exclusivamente en su rol de difusores de las medidas gubernamentales.

El CNE realizó una intensa labor en el área pedagógica para "elevar la preparación y el nivel cultural del magisterio” (Boletín de la Secretaría de Educación, 1948, p. 17). Además de ciclos de charlas destinadas a divulgar los fundamentos de la reforma y el trabajo con los problemas pedagógico-didácticos cotidianos (Res. CNE, 9 de abril de 1948) coordinó su trabajo con el plan de política cultural diseñado por la Comisión Nacional de Cultura, presidida por Antonio P. Castro desde 1948. Este organismo, que tuvo entre sus integrantes al Delegado Interventor del CNE Federico Daus, extendió su acción a través de un proyecto orientado a incentivar las manifestaciones artísticas. El primer paso, expuesto en la Guía Quincenal de la actividad cultural y artística argentina, consistió en difundir actividades que abarcaron las artes plásticas, ciclos de programas radiales y publicaciones periódicas (junio de 1948, p. 73). El plan ideado para el público en general halló en la escuela un espacio fértil para su desarrollo.

\subsubsection{La difusión de las manifestaciones culturales: la acción de los maestros en los clubes escolares}

La intención de que "todo establecimiento de educación sea centro de irradiación y de atracción cultural y social” y generara nuevos vínculos con el medio social (Decreto 26.954,18 de septiembre de 1947) se materializó claramente en los clubes escolares. El programa había sido creado, según la disposición del ejecutivo, con el fin de rescatar al niño de la calle y extender su tiempo dentro de la institución. Según la revista pedagógica oficial Guión, ductor itineris:

El club escolar es la escuela abierta para [que] los vecinos, fuera de las horas de clase, se reúnan a leer, a charlar, a jugar, a usar racional y ordenadamente de las comodidades que el establecimiento posea, bajo la dirección e inspiración del personal directivo y docente del mismo (mayo de 1948, p. 40-41).

Los clubes extendían la acción del personal fuera del aula y de los horarios de cada turno. Orientados hacia la formación integral del alumno, los maestros de grado y los especializados debían complementar la labor cotidiana con actividades estéticas, físicas y recreativas, manifestaciones artísticas, lectura, teatro de títeres, música y danza. Entre las acciones sugeridas se encontraban, la exhibición de películas, funciones de teatro y audiciones organizadas por orquestas (Exp.22154/P/1948, CNE). Para ello, Antonio Castro, en coordinación con la administración de las escuelas primarias, puso a disposición bandas de música, el Teatro Infantil Labardén, el Teatro de la Escuela para Adultos y la Orquesta de Música Popular dirigida por Juan de Dios Filiberto (Res. CNE, 20 de abril de 1948). Sin bien el apoyo externo fue significativo, la elaboración de situaciones de aprendizaje estuvo bajo la responsabilidad de los docentes de cada grado. 
Las revistas educativas, principales proveedoras de sugerencias de trabajos para el aula, pusieron a disposición diferentes recursos. Al respecto, el anuncio de La Obra da indicios de cómo fueron recibidas estas medidas por parte del magisterio.

A nuestros lectores

a partir del próximo número publicaremos en todos una página con poesías breves, comedias y otras piezas sencillas representables en el teatro escolar, material didáctico que ofreceremos a nuestros colegas para facilitarles su cometido en la labor que se les está exigiendo en muchas escuelas con motivo del funcionamiento de los clubes infantiles (10 de mayo de 1948, p. 141).

La planificación de las actividades de danza y música fueron confiadas al Inspector de Música del CNE, el reconocido compositor Athos Palma. Sus intereses coincidían con el espíritu nacionalista de la época, la reivindicación del regionalismo y de la expresión folklórica. Entre las propuestas se hallaban conciertos vespertinos de la Orquesta Sinfónica de Radio del Estado, los conciertos mensuales de las Bandas de Policía y Municipal y de la Orquesta Folklórica Municipal dirigida por Juan de Dios Filiberto, la colaboración mensual del Coro Polifónico del Conservatorio Nacional de Música y el Arte Escénico, la Escuela de Orquesta y los coros infantiles, las presentaciones del Conjunto Folklórico, conjuntos de música de cámara y transmisiones semanales de la comedia que se representaba en el Teatro Nacional Cervantes (Expediente 6104/I/1948, CNE). Como ocurrió con otras experiencias, la difusión destinada a la comunidad educativa no se caracterizó por la novedad en los contenidos sino por su lugar dentro de una política pública y el rol de los maestros en la democratización de las manifestaciones artísticas que existían.

Los clubes escolares, que habían funcionado sin éxito durante los gobiernos precedentes, cobraron en los primeros años peronistas un nuevo significado. El impulso de estas actividades formó parte, en palabras de Yanina Leonardi (2014a), del acceso de la familia obrera "a la recreación y al consumo cultural...destacando este objetivo dentro del aparato publicitario” (p. 241). Al respecto, el archivo Prisma contiene entre sus registros un documental realizado en 1948 por el Cine Escuela Argentino en el que se compilan imágenes a modo de propaganda informativa destinada a la comunidad.

El film muestra a los maestros, de impecables guardapolvos blancos, acompañando a los grupos de niños de diferentes escuelas de la actual ciudad de Buenos Aires. Entre las actividades realizadas por los alumnos se observan juegos de ping-pong, paseos en el río, juegos de mesa, construcción de barriletes, coros, bailes tradicionales y danzas folklóricas. La participación activa de la sociedad aparece en diferentes escenas, en una función de teatro infantil dirigida por una religiosa o en una obra de títeres realizada por un ayudante o auxiliar. En palabras del locutor, "padres, hermanos, parientes, el barrio entero y con él, el auténtico pueblo ya es parte vital de la nueva escuela”. Las palabras resuenan grandilocuentes y son acompañadas por tomas reiteradas y planos generales de las familias ocupando cada espacio de la institución. $\underline{1}$

Desde el medio gráfico, la revista Guión, ductor itineris, editada por el CNE y destinada a los maestros, describió una situación similar percibida por uno de los reporteros en la inauguración de un club. Según el visitante, se observa "un gentío numeroso...muchos niños; muchos pequeñitos; 
mujeres y madres; pocos hombres” a la espera de la presentación de los bailes regionales, coros escolares y películas programados (junio de 1948, p. 38). Estas actividades se articularon directamente con la oferta de programas, cursos y actividades de capacitación para los docentes.

\subsubsection{Música, dibujo, teatro, cine: las propuestas, programas e instituciones de capacitación y divulgación de las manifestaciones artísticas para los maestros}

Una de las formas de democratización de las manifestaciones artísticas fue la apuesta a la enseñanza, estudio y difusión de las tradiciones nacionales que incluyó, desde la fundación de la Escuela Nacional de Danzas Folklóricas Argentinas hasta la idea de la elaboración de una colección de cuentos y leyendas con música por parte de la Comisión de Folklore y Nativismo del CNE. Estas propuestas reorientaron lo realizado por la Comisión Nacional de Música durante los años anteriores y lo aplicaron a los clubes de las escuelas, "verdadero lugar en el que se deben realizar las manifestaciones estéticas, pues se cuenta con auditorio espontáneo y nutrido” (Guión, ductor itineris, junio de 1948, p. 36). Paralelamente, brindó cursos de teoría y práctica del folklore cuyo contenido tradicionalista fue el eje para formar un "muy escogido grupo de maestros que, además de sus amplios conocimientos musicales, poseerán una vasta erudición sobre la teoría del folklore, la historia de la música argentina y la coreografía específica de todas vernáculas” (Educación Común en la capital, provincias y territorios nacionales, 1948, p. 18). Para el quehacer en las escuelas, El Monitor de la Educación Común puso en circulación un suplemento que contenía actividades relacionadas con el folklore y las danzas argentinas. Estas manifestaciones artísticas fueron presentadas como una extensión de la educación física (junio de 1948). La revista ofertó a los maestros, ideas y actividades para cada clase, juegos, adivinanzas, acertijos, deportes de habilidad, excursiones y una serie de bailes sencillos como el gato o la chacarera.

La inspección de Dibujo impulsó actividades para el magisterio en general. Planificaron desarrollar un programa de carácter pedagógico dedicado al personal especializado y a los docentes de las escuelas de la Capital Federal y de las escuelas particulares, realizar reuniones periódicas para concretar su muestra permanente y organizar viajes para conocer las exposiciones artísticas escolares que se desarrollaron en Uruguay y en Bolivia (Educación Común en la capital, provincias y territorios nacionales, 1948). Las propuestas vinculadas con el teatro escolar no presentaron quiebres significativos en sus contenidos. A diferencia de "Un Teatro para los Niños de la Nueva Argentina”, experiencia que vinculaba el sistema educativo y el aparato propagandístico del Estado (Leonardi, 2014b, p. 63), la incorporación del teatro en los programas de estudio no tenía como fin la apreciación de la manifestación artística en sí misma sino su utilización como recurso para la enseñanza de la lengua. Las piezas de Germán Berdiales, vigentes en la literatura infantil desde los años treinta o las obras para títeres de Pongetti y Camargo fueron ofrecidas por La Obra, atentos a aquellos docentes con dificultades para adaptar obras literarias tradicionales. Estos autores, además, formaban parte de la bibliografía sugerida por el CNE para el trabajo en el aula. $\underline{2}$

Otros elementos ofrecidos por el Estado a los maestros fueron la radiotelefonía y la cinematografía. Convencido de su eficacia educativa, el poder ejecutivo encomendó a Jorge Arizaga la organización del Consejo Asesor de la Comisión Nacional de Radio enseñanza y Cinematografía Escolar. Según uno de los periódicos de Santa Fe: "El cine y la radio, han sido incorporados por la Secretaría de 
Educación para contribuir a la práctica de la enseñanza. La Comisión de Radio enseñanza y Cine Escolar [...] ha organizado una filmoteca con más de cincuenta películas cortas para ser exhibidas en las escuelas y ha preparado en colaboración con empresarios de distintos cinematógrafos programas gratuitos de cine educativo [...] Simultáneamente y a través de la radiotelefonía serán desarrollados los programas educativos que llegarán a todas las escuelas del país” (El Orden, 13 de junio de 1948).

La Comisión Nacional de Radiodifusión propuso iniciar un ciclo de audiciones docentes destinado a alumnos del ciclo superior de la primaria y del nivel secundario. Para cumplirlo, cada docente debía readaptar el contenido de la trasmisión a las cuestiones trabajadas en el aula, elegir las audiciones que resultaran de interés, preparar al alumnado, complementar con imágenes y realizar un cierre de la clase. Las proyecciones de películas no tenían en sí un fin recreativo sino una función “ilustrativa” (Guía Quincenal de la actividad cultural y artística, junio de 1948, p. 71). La Radiofonía estaba al servicio de la enseñanza y transmitía conciertos, cantos escolares, efemérides, música folkórica, poesía, dramatización de hechos históricos, conferencias, clases modelo, leyendas, consejos para madres, biografías y conferencias para los maestros (La Nación, Justa, Libre y Soberana, 1950, p. 255). La adaptación y selección de los contenidos estaba en manos del personal de cada escuela.

Con respecto a la actividad artística, el CNE fundó nuevas instituciones destinadas a incentivar la creación artística, entre ellas, el Departamento Cultural del Consejo Nacional de Educación y el Primer Salón de Artes Plásticas del Magisterio. El primero tuvo sus fundamentos en la necesidad de no limitar la actividad cultural del maestro, su vocación o posibilidades de creación. El espacio, señalan las fuentes oficiales, tenía como objetivo "que los señores maestros den conferencias, asistan a ellas, prohíjen exposiciones de arte, expongan sus obras y conciertos de música, se vinculen con instituciones de análoga inspiración” (Res. CNE, 4 de junio de 1948). El segundo, estaba destinado al personal docente y administrativo del país y contaba con varias secciones, pintura, esculturas, grabados, dibujos, ilustraciones para libros, escenografías para teatros y títeres y decoración. Según el CNE:

La labor de cultura del maestro, en su más noble acepción, no termina con el horario de clase de la escuela, sino que se acendra y cultiva en los fueros del espíritu más allá de su tarea pedagógica [...] enriqueciendo su acervo cultural, artístico o científico (El Monitor de la Educación Común, 1948, pp. 3-4).

El maestro fue interpelado como consumidor de cultura y "a la hora de planificar el ocio [en este caso para el magisterio] el Estado peronista optó por un ocio instructivo, que pretendía hacerles llegar a ese grupo un acervo cultural de índole nacional y universal” (Leonardi, 2014a, p. 248). El plan de democratización de la cultura de los primeros años peronistas alcanzó a los agentes estatales encargados de difundirla. La nueva función de la escuela fue acompañada por espacios de perfeccionamiento y desarrollo personal. La creación de instituciones, cursos y conferencias difundidas por el CNE durante 1948 dan cuenta de una mirada hacia el sector que matizó el rol de funcionario estatal, característica fundacional magisterio, con un nuevo impulso hacia la profesionalización de su labor. 
Si bien en este trabajo no se evalúa su repercusión o recepción, las resoluciones del interventor del CNE evidencian que la relación del peronismo con el magisterio fue producto de un entramado de intereses pedagógicos, sociales y culturales y no siguió solamente la lógica de la cooptación, persecución o enfrentamiento. Futuras investigaciones serán necesarias para profundizar la recepción que tuvieron las medidas en las instituciones y en la comunidad educativa.

\section{Consideraciones finales}

En 1948 la última gestión del CNE dirigió una serie de medidas destinadas a reorientar el perfil del maestro en ejercicio. Las propuestas innovadoras impulsadas desde el oficialismo se desarrollaron en el marco de un proyecto político que autoproclamaba "perseguir la reivindicación integral del hombre argentino” (Marechal, 1947, p. 126). Desde esa línea, y en sintonía con las políticas democratizadoras, la burocracia educativa peronista planificó una serie de acciones complementarias que tuvieron en cuenta elementos novedosos, no por su contenido sino por su incorporación a los fines político-ideológicos de un modelo centralizado de difusión de las manifestaciones culturales. A diferencia de las gestiones anteriores, la administración del CNE en 1948 diseñó una estrategia de intervención en el aula en coordinación con la Comisión Nacional de Cultura.

La última gestión del CNE dio a conocer que su mirada hacia el magisterio no se limitó solamente a un objetivo partidario y asumió el problema de la formación cultural docente como uno de los elementos necesarios para el paso hacia la educación integral de un sistema en expansión.

\section{Notas}

1 El corto dura 5:46 minutos y puede consultarse completo en http://www.archivoprisma.com.ar/registro/vacaciones-utiles-circa-1948/

2 Para la bibliografía recomendada por el CNE a los maestros véase: El Monitor de la Educación Común, 1949, http://repositorio.educacion.gov.ar:8080/dspace/handle/123456789/99369

\section{Fuentes primarias}

Argentina. Ministerio de Justicia e Instrucción Pública. (1947). La educación nacional. Buenos Aires: Subsecretaría de Instrucción Pública.

Argentina. (1950). La Nación, Justa, Libre y Soberana. Buenos Aires: Control de Estado de la Presidencia de la Nación.

Argentina. Comisión Nacional de Cultura. (1948). Guía Quincenal de la actividad cultural y artística.

Argentina. Consejo Nacional de Educación. (1945). Educación Común en la capital, provincias y territorios nacionales 1943. Buenos Aires: Talleres Gráficos del Consejo Nacional de Educación. 
Argentina. Consejo Nacional de Educación. (1948). Expediente 22.293-C-1948. Departamento Archivo intermedio. AGN.

Argentina. Consejo Nacional de Educación. (1948). Expediente 27.747. Departamento Archivo intermedio. AGN.

Argentina. Consejo Nacional de Educación. (1948). Expediente 28.226-C-1948. Departamento Archivo intermedio. AGN.

Argentina. Consejo Nacional de Educación. (1948). Guión, ductor itineris.

Argentina. Consejo Nacional de Educación. (1947-1948). Suplemento de El Monitor de la Educación.

Argentina. Ministerio de Educación. Consejo Nacional de Educación. (1949). Educación Común en la capital, provincias y territorios nacionales 1947. Buenos Aires: Talleres Gráficos del Consejo Nacional de Educación.

Argentina. Ministerio de Justicia e Instrucción Pública. (1948). Boletín de la Secretaría de Educación de la Nación. Buenos Aires: Secretaría de Educación de la Nación.

Argentina. Presidencia de la Nación. Secretaría Técnica. (1946). Plan de gobierno 1947-1951. Buenos Aires: Presidencia de la Nación.

Arizaga, J. (1947). “Aplicación del plan de gobierno en la enseñanza primaria”. El Monitor de la Educación Común, 897-900, pp. 35-53.

Argentina. Consejo Nacional de Educación. (1947-1948). El Monitor de la Educación Común.

El Orden, 13 de junio de 1948.

La Obra, revista de educación. (1939, 1947-1949). Buenos Aires: Ediciones La Obra.

Marechal, L., (1947). Proyecciones Culturales del Momento Argentino. En Argentina en marcha, Buenos Aires: Comisión Argentina de Cooperación Intelectual.

Ministerio de Justicia e Instrucción Pública. (1948). Vacaciones útiles. Argentina. Recuperado de http://www.archivoprisma.com.ar/registro/vacaciones-utiles-circa-1948/

Número extraordinario dedicado a las actividades de educación física de Clubes Escolares, (junio de 1949). El Monitor de la Educación Común.

\section{Bibliografía}

Avellaneda, A. (1983). El habla de la ideología. Modos de réplica literaria en la Argentina contemporánea. Buenos Aires: Sudamericana.

Bernetti, J. L., y Puiggrós, A. (1993). Peronismo: cultura política y educación (1945-1955). Buenos Aires: Galerna.

Cammarota, A. (2010). El Ministerio de Educación durante es peronismo: ideología, centralización, burocratización y racionalización administrativa (1949-1955). Revista Historia de la Educación 
Latinoamericana, 15, 63-92. Recuperado de http://www.rhela.rudecolombia.edu.co

Carli, S. (2002). Niñez, pedagogía y política. Transformaciones de los discursos acerca de la infancia en la historia de la educación argentina entre 1880 y 1955. Buenos Aires: Miño y Dávila.

Finocchio, S. (2009). La escuela en la historia. Buenos Aires: Edhasa.

Fiorucci, F. (2012). El campo escolar bajo el peronismo, 1946-1955. Revista Historia de la Educación Latinoamericana, 18, 139-154. Recuperado de http://www.redalyc.org/articulo.oa? $\underline{\mathrm{id}=86925890007}$

Gvirtz, S. (1991). Nuevas y viejas tendencias en la docencia. Buenos Aires: Centro Editor de América Latina.

Gvirtz, S. (1999). El discurso escolar a través de los cuadernos de clase. Buenos Aires: Eudeba.

Iglesias, A. (2012). Interpelando al Magisterio. Un análisis desde El Monitor de la Educación Común (1943-1949). Propuesta Educativa, 21, 93-100. Recuperado de http://www.propuestaeducativa.flacso.org.ar/indice.php?num=38

Leonardi, Y. (2014a). Ocio y arte para los obreros durante el primer peronismo. Revista Mundos do trabalho, 12, 239-249. Recuperado de https://periodicos.ufsc.br/index.php/mundosdotrabalho/article/viewFile/1984$\underline{9222.2014 v 6 n 12 p 239 / 29738}$

Leonardi, Y. (2014b). Formaciones teatrales de intervención política en el mundo de la infancia durante el primer peronismo. AURA, 2, 49-66. Recuperado de http://www.ojs.arte.unicen.edu.ar/index.php/aura/article/download/99/93

Lionetti, L. (2007). La misión política de la escuela pública: formar a los ciudadanos de la república (1870-1916). Buenos Aires: Miño y Dávila Editores.

Pineau, P. (1994). El concepto de “educación popular”: un rastreo histórico comparativo en la Argentina. Revista de Educación, 305, 57-278.

Plotkin, M. (2007). Mañana es San Perón: propaganda, rituales políticos y educación en el régimen peronista 1946-1955. Buenos Aires: Eduntref.

Rein, M. y Rein, R. (1996). Populismo y educación: el caso peronista (1946/1955). IICE, 8, 50-57.

Somoza Rodríguez, M. (2006). Educación y política en Argentina (1946-1955). Buenos Aires: Miño y Dávila.

Southwell, M. (2011). Docentes: la tarea de cruzar fronteras y tender puentes. Explora. Las ciencias en el mundo contemporáneo, 2011. Recuperado de http://explora.educ.ar/wpcontent/uploads/2010/04/PEDAG04-Docentes1.pdf

Torre, J. C. y Pastoriza, E. (2002). La democratización del bienestar. En Torre, J. C., Los años peronistas (1943-1955) (pp. 257-312). Buenos Aires: Sudamericana. 